\title{
Envisioning atmospheres of spectacle and activism. Utopia and critical urbanism instruments for the reclamation of the fragmented territories of the WALL and the MALL.
}

\author{
Manfredo Manfredini \\ University of Auckland, New Zealand \\ Faculty of Creative Arts and Industries \\ m.manfredini@auckland.ac.nz
}

\begin{abstract}
Woundedlands are places of crisis of the civic sphere where architecture contributes to escalate the agency of forces that annihilate associative, differential and commoning processes. They are exemplary expression of the destructive capacity of contemporary technology to increase control, abstraction and exclusion. This paper addresses two salient Woundedland types: the WALL and the MALL.The WALL-a harsh boundary displacing and negating access to the stranger-epitomizes the increasing instances of unmovable and unforgiving socio-spatial divides. The heavily armed Korean Demilitarized Zone is chosen as an egregious walling example. The MALL-a supreme urban embodiment of digitally enhanced urban de-commoning and homogenizing forces-typifies the postconsumerist spectacular production of implanted and exogenous pseudo-civic centralities. The heterotopic metropolitan centre of Sylvia Park-the main malled centre in New Zealand-is selected as a representative instance of the dissociative enclaves of spectacle. Two major phenomena characterize the spatial production of these Woundedlands: pervasive translocalization - the diffusing mobilization of territorialization patterns-and multiassociative transduction-the iterative production of combinant and immersive metastable spatialities. This paper presents design proposition sets that address these phenomena and reimagine these Woundedlands as productive utopias: Wonderlands of reappropriated and (re)creational spatialities. These are cultural responses to the contemporary mode of production, challenging and transmuting its alienating apparatuses. They recast symbols of geopolitical and mercantile warfare into possible analogue worlds with a rich mix of instrumentalities that support existing counterforces. They have metastable spatialities that affirm the emerging forms of communing, relationality and differentiation of the digitally augmented social networks. The propositions contribute to a better cultural understanding of the current spatial paradigm. Alternative discursive frameworks of coordinated narratives with scenario-based and context-specific sign-value articulations support tightly crafted chains of recoded elements that leverage on the agency of desire. Allegorical fabulatory proses envision (extra)ordinary commoning machines for pluralism, justice and jouissance affirm the value and necessity of utopia.
\end{abstract}

Keywords: public space, urban commons, transductive translocalisation, Korean demilitarised zone, shopping malls

To cite this article:

Manfredini, M. (2019). Envisioning atmospheres of spectacle and activism. Utopia and critical urbanism instruments for the reclamation of the fragmented territories of the WALL and the MALL., The Journal of Public Space, 4(4), 83-108, DOI 10.3289I/jps.v4i4.1235

This article has been double blind peer reviewed and accepted for publication in The Journal of Public Space.

(c) (5) This work is licensed under a Creative Commons Attribution - Non Commercial 4.0 International License https://creativecommons.org/licenses/by-nc/4.0/ 


\section{Part I}

\section{Framing spatialities}

Pervasive translocalisation and multiassociative transduction are key phenomena of contemporary spatial production that critically challenge the integral resilience of present-day urban communities. Their progressive diffusion and dynamism are profoundly transforming our society. Translocalisation is the constant redefinition of territorialisation patterns due to an increasing mobilization of people and things that dissipate the continuity, cohesion and permanentness of traditional social and spatial networks. Reconfiguring territorial patterns involves migrations on all spatial scales, from the local to the global, with progressive temporal instability (Brickell and Datta, 20I I; Greiner and Sakdapolrak, 20I3; Kazig, Masson and Thomas, 2017). Transduction is a transmutative operation that implies the coming together of heterogeneous forces in either progressive, iterative processes or irregular ones that restructure given domains into provisional unities through the diffusion of an exogenous activity (Simondon, 20I3 [1964-89]). It produces recombinant metastable spatialities that become increasingly powerful due to the capacity of augmented and mixed realities to create fully immersive and intensely evenemential instances (MacKenzie, 2006).

To address how the effects of these disrupting phenomena redefine the roles, mission and instruments of architecture in our lived, perceived and conceived everyday spatialities, the Woundedland project studies contexts where this transition is particularly acute: places where this spatial restructuring incessantly produces conditions of radical deterritorialisations and reterritorialisations. In these places, disruptive and momentous geopolitical expansionist interests of primary global organizations threaten the wellbeing of their communities, undermining their resilience. The WALL and the MALL are the two salient types of these territories in crisis addressed in this research. The WALL (acronym for wall with augmented liminality) is the global epitome of divide strategies that displace and negate access to the stranger. It reifies narratives of sovereignty, instrumentally staging stalled, latent or preposterous conflicts with policed, unmovable and unforgiving boundaries that dissociate the locale by inhibiting migration and networked translocalism. A crucial case of ruthlessly enforced walling is found in the key area of the heavily armed Korean Demilitarized Zone (DMZ) (Horvath, Bența and Davison, 2019). The 250-km-long Demarcation Line separating the two Koreas constitutes the core of a complex array of boundaries originating from the post-WWIIdesignated border on the 38th parallel (Gelézeau, 201 I). Iterations, extensions and mobilizations have resulted in a set of highly contested territories, where exogenous interests exert tight control through major systemic apparatuses. The DMZ is a space where simulation and reality are indiscernible. It constitutes a major global political stage where the representation of highly choreographed dramas intertwines with actual confrontations and tragedies. The parallel plays enact pieces oddly co-written by authors of multilayered geopolitical hegemonic apparatuses in unstable internal alliances and wavering external conflicts. Scarcely coherent aims, volatile strategies and erratic tactics inform this permanently activated political stage, making it a resonance machine (Connolly, 2005) governed by a multiplicity of semi-dependent apparatuses that often direct their "characters" to perform solipsistic dialogues and absurd practices. Powerful simulative mechanisms tightly curate and control public perception, expression and understanding, 
cobbling together objective, symbolic and experiential authenticities that range from the fabrication of spectacular and eventful encampments to the construction of demonstrative prosaic and ordinary settlements. Examples of the former are the harmoniously designed Joint Security Area, the fuori scala Panmunjom flagpoles and the experientalised Third Tunnel of Aggression (the main infiltration underground passages turned into primary "dark tourism" attractions). Instances of the exogenous pseudocivicness of the latter are the idyllic Peace Village in the Northern part of the DMZ and the assimilatory Strategic Villages engrafted within the Civilian Control Zone on the Southern side of the DMZ (Seo, 2018).

The MALL (acronym for mall with augmented liminality) is the emerging shopping-centre type that in recent years has supplanted the urban centrality of the fixed, everlasting, cathedral-like and fully embedded placeness of the modern American-style mall (Ritzer, 2005: 6-9). The MALL has redefined itself to become an iterating simulative urban core that is at the same time an assembling agent characterised by multiplicity and eventuality, and an assembled element with functionally recombinant, swiftly scalable and swinging situated placelessness. Consumption has expanded to the point of exhausting even its supreme affirmative institution. The depletion of the geographical referentiality of the prototypical generic space of the consumption cathedrals of the networked city (Koolhaas, 2002) has generated an allotype of post-consumption that merges the complex spatialities of flow (Castells, 2000) with the ambivalent meta-public common spatialities of the post-civil urbanity (Dehaene and De Cauter, 2008; Manfredini, 2017;). The MALL, as a more-than-consumerist and digitally enhanced technosphere of spectacular transduction, reformulates the question of the Right to the City by instantiating a completely new condition of what Lefebvre (2003 [1970]) describes as the impoverished "urban world reduced to its economic elements" (35). It indeed constitutes a sort of public space driven by, as Harvey (2008) poses, the relentless dynamics of capital accumulation that, to expand the surplus production at a compound rate, has "the perpetual need to find profitable terrains for capital-surplus production and absorption" (24). This condition is at the core of the MALL's relentless global pervasion in urban spaces with neoliberalism-driven governance, such as the main Australasian cities. Here, the MALL representative was found at Sylvia Park, one of the main metropolitan nodes of the polycentric urban area of Auckland, New Zealand. As an epitome of the modern urbanisation process, Sylvia Park mall alienates itself morphologically, typologically and socially from its prime historical, cultural and environmental context. Its urban area with low population density (approximately 19 people/ha) is in strong contrast with the intense 15-million yearly patronage of the 200+ stores mall. Its social and physical infrastructures are hegemonic, limit community interaction, critically disempower the collective and, consequently, inhibit the pluralistic practices that are core to civic growth.

\section{Counterspatialities}

As emplacements at the forefront of the implementation of the most advanced ICT applications, the DMZ and Sylvia Park Woundedlands prominently represent the changing technological framework of our relational life. Given their socio-cultural relevance and popularity-being the top Korean touristic destination and the premier 
New Zealand malled urban centre-they are de facto laboratories of the transformation of our collective everyday practices.

With regard to the MALL of Auckland, recent studies have shown how the profusion of the new ICT technologies among all stakeholders have developed the MALL as a new type of civic commons that importantly rearticulates and activates the public sphere (Manfredini, 2019a, 2019b).The abundant evidence of the MALL's outstanding performance in both social and spatial relationality, found with analysis of crowdsourced data from the visual-based geolocative social media platform Instagram, confirms the strong growth of associative forms antagonist to the fragmentation and domination of the hegemonic apparatuses. Network analysis detected an extraordinary community vitality; visual content research captured how the imposed image of the city morphed into collectively reappropriated spatialities of representation and daily routines. Yet, the critical interpretation of these counterspaces-which escalate the associative forms on the basis of the collective, the civic and the political—reveals their subjection to an ambivalent agency (Foth, Brynskov and Ojala, 20I 5; Fuchs, 20 I4; Manfredini, Zamani Gharaghooshi and Leardini, 2017). Participatory production-identified as the key triggering phenomenon-manifests an inborn "performative paradox" (Manfredini, $2019 a$ ); while introducing counterspaces of differentiation and autonomy that destabilise the hypercontrolled superstructure of the instrumentally politicised and financialised virtualisation of the civic, this kind of production also generates manifold nested heterotopic spheres that heavily rely on the very same superstructure that it opposes. In the DMZ, investigation of everyday practices showed that analogue occurrences of digitally diffused counterspatial commoning are widespread (Gelézeau, 20I I; Kim, 20 I5; Manfredini, 2019d). Examples range from engagement with momentous identity affirmation actions, such as keeping reunification narratives active by hanging annotated photographs and prayer ribbons on the South Korean Civilian Control Line fence in Imjingak Park in Paju (one of the limits of the civilian access situated some $3.5 \mathrm{~km}$ south of the DMZ), images of which are widely circulated on the web, to taking active part in grassroots political movements, such as the masses that took to the streets for civic protests which were coordinated through social media in the South Korean capital, Seoul, to raise awareness of relationship issues between North and South Korea. The new translocalised and transducted commons strengthen the political and civic centrality of these places by developing site-specific and locally rooted communities of practices and social hubs. These communities establish effective mechanisms that empower the political sphere and reintroduce the right to the networked city in opposition to the overpowering antagonist forces that disenfranchise and dispossess the citizen. The reappropriation of the political dimension of the daily practices and acts at the core of the Woundedlands produce instances of concrete utopias that foreshadow possible alternatives:Wonderlands of reimagined, truly productive and diverse participative common spatialities.

\section{Setting speculative discourses of commoning patterns}

The complex apparatuses of the dominating powers are investigated to better understand the significance of specific spatial production resulting from the superimposition of multiple deterritorialisation and reterritorialisation processes. Our studies aim to shed light on the manufacturing techniques and impacts of these 
assemblage systems. They address the key elements of crisis in order to develop interpretations that help redefine architectonics of wonder, focusing on the agency of the opposing production patterns. On the one hand, they explore the way some patterns diminish the social, material and cognitive relationality of individuals and communities, eroding the terrain of established commoning practices. These forces are seen, as posited by Lefebvre (199I [1974]: 50-5I), as producing sameness and homogenization ("induced diversity") to create a space of abstraction that progressively "set[s] itself up as the space of power." They are exerted by the dominant power of major organizations, working to occlude the public sphere (Calhoun, 1992) and inhibit communicative acting with spatial overdetermination and closure (Sennett, 2018), producing deep wounds in the civic socio-spatial body where societal organs become fragmented, displaced and depoliticized. The civic commons - the most affected institution-are used by hegemonic powers as primary instruments to stabilize and enhance their strength and capacity. Through the establishment and implementation of complex administrative mechanisms and knowledge structures, the commons are cast into propagandistic spectacularised deployments of geopolitical and economic apparatuses. Their conclusive effect is the splintering of communities and the relentless annihilation of the communities' socio-spatial relationality.

On the other hand, there are agencies that support autonomy and self-determination through open, inclusionary, collaborative and commoning-based processes (Linebaugh, 2007). These forces produce and are produced by a maximal difference that re-establishes democratic decision making and control on urban life, celebrating both bodily and experiential particularity (Lefebvre, I99। [1974]: 372; Merrifield, 2000: 76; Purcell, 2003: 578). By affirming the right to centrality and diversity, they empower citizens and communities to regain control of spatial production. Through the activation of open exchange and dialogue, they establish "agonistic pluralism" conditions (Mouffe, 2008) with "rich mixes of instrumentalities" (Harvey, 20 I I: 102) that reassemble the collective dimension of the civic and re-establish commoning practices and institutions that protect the citizens against the attempt of external hegemonic economic organizations to expand their power. Paradoxically, while the transductive capacity of the apparatuses of the hegemonic powers to redefine contexts and create theatrical or spectacular otherness is proportional to its translocalising and transductive potential to abstract and splinter communities and ecologies, dominate behaviours and control perceptions of individuals and groups, at the same time, the intense digital translocalisation and transduction of the apparatuses enable communities to gain independence, selfdetermination and appropriation of their own spaces.

\section{Part II}

Co-authored with Sunee Yoo, University of Auckland, New Zealand

\section{Design strategies for commoning and enjoyment-desiring machines}

Individual studies on specific elements of the grand meta-narratives deployed in selected DMZ and Sylvia Park Woundedland assemblages were explored to trigger scenariobased creative speculations that affirm the counterforces instituting commoning machines for cohesive, resilient and productive social, physical and symbolic spatialities of 
pluralistic jouissance. Specific topoi were used as discursive sites for proses that reimagine utopia. Place-based and sign-value articulations envision alternative spatial conceptions that contrast with the dominative symbolic warfare and spectacular consumerism of the contemporary mode of production. The staged WALL warfare was addressed with critical elaborations that foreground both its dioramic geopolitical theatralisations into a contingent or meaningless structural form (Jameson, 2007 [ 1992]: 126) that adequately frames the practices of reappropriative commoning. The spectacularised MALL was approached as a full-blown heterotopic space where, while citizenship is negated by uncanny financialisation, there is simultaneously a growth of important reassociative counterspatialities that contest the totalising consumption and affirm freedom, participation and land custodianship.

The project proposals are assemblages for the affirmation of the right to the civic by supporting the integral wellbeing of citizens and communities, which are designed to deploy the productive agency of desire. They envision couplings of separate and independent entities that institute commons for integrated activities. They outline complex associations of elements that produce desiring machines (Deleuze and Guattari, 1983: 340 et passim), integrating systems for production, sharing, interaction, encounter, politics, creativity and culture that also generate enjoyment and pleasure.

The propositions result from the integration of two design strategies instituting machinic processes of translocal restorative infrastructuring and transductive restorative recoding. The first is a strategy developed through a relational method that associates transient (translocal) elements which are spatially and temporally displaced. The recomposition of scattered elements into advanced institutions of the "world in common" is grounded in instantiated critiques of both the abstractive apparatuses and the countering forces. The new commons embody desiring-formation processes, which combine distant and heterogeneous elements in composite assemblages of material and immaterial infrastructures for the activation of the new commons that increase capacity and agency of both local and translocal communities.

The second, the transductive restorative recoding, is a transformational strategy that activates the new infrastructure created through the translocal restorative process. It employs an allegorical, context-specific narrative method that gives consistency and cohesion to the translocal metastable environments. These are scenario-based narratives for the establishment of critical topoi of "production of production," where design uses its discursive capacity to create a space for creative engagements with possible worlds (Purcell, 20I4), proposing tight signifying chains of fluidly recoded realms of coded institutions: moments of utopia made accessible as parodic or fabulatory proses of the ordinary.

Focusing on the creation of public commons that support socio-spatial relationality between people and their environment, the DMZ and Sylvia Park propositions adopt space-generation processes aimed to establish collective territories and "freespace" where social cohesion and dynamic differentiation empower individuals and communities. Challenging the conventional role of architecture, allegory is used to shape finely tuned machinic narratives involving desire as the driver of change for sociopolitical (the WALL) and socio-economic (the MALL) conditions of crisis.

The studies do not focus on the necessary pragmatics of built projects; rather, they examine and demonstrate the power of allegory in architecture by deploying supersignifiers that disestablish the exogenous/hegemonic apparatus and recode its 
abstractive deterritorialisations. The design propositions reassociate elements by tapping into the limitless/unmitigated potential of narrative, parody and allegory to decipher and critique the existing socio-political spatialities of the chosen WALL and MALL, pulling apart and examining the spectacularised yet covert forces of the systemic apparatuses. The narratives create composite antagonist assemblages to such existing dominant external forces-namely, the political interests of both the local North and South Korean governments and the global superpowers associated with the DMZ, and the economic interests of expansionist forces associated with Sylvia Park. They ultimately reinvigorate the critical discourse on the potential role of space for dialogue in the socio-political and socio-economic contexts of the DMZ and Sylvia Park and, at large, in all civic commons in the age of translocal and transductive territorialisations.

\section{Design propositions}

The projects have as primary objective the social, political and cultural reconciliation of the divided spaces. They explore complementary topics that address the tension caused by the disruptive spatial fragmentation, abstraction and spectacularisation of these spaces and study the needs and desires of their disjoint communities. Each topic develops an interpretation that integrates relational, behavioural and perceptive dimensions to shed light on major political and economic issues related to the right to the city. The adoption of new technologies enables the democratisation of these contested spaces implementing free spaces of digitally enhanced transductive spatialities (e.g., integrating virtual, augmented and mixed reality). Through an analysis of territorial palimpsests, which use space as the prime medium, the projects engage with specifically situated aspects of complex issues and inform articulated expressions that use critical allegory to envision spatial conditions with alternative modes of social, material and cultural production. Storytelling is used to present new urban commons in which society is no longer prey to the power or commodity culture of the disciplinary spaces of theatricalised geopolitical or economical dominations. Rather, it is supported in its affirmation of by new liberated commons with central, open, indeterminate, translocal spatialities for encounter, sharing and dialogue, where the conflicts of multicultural and diverse components are recognised as positive, creative and productive forces.

\section{Korean Demilitarised Zone}

To support the multidimensional reconciliation of the DMZ divided spatialities, the projects explore key elements of the tension between the reality and simulatory spectacle that affect the disjoint communities of the Korean Peninsula along the border. This includes the examination of representative spatialities of local and translocal groups that counter the poverty of social and civic connections by instituting productive relational, behavioural, and perceptive relationalities. Through allegoric narratives of reconciliation, the utopian discourse is formed around super-signifiers that raise complex issues through the association, in nested assemblages, of spatialised elements belonging to the very political conditions of the sites theatre (figure I). 


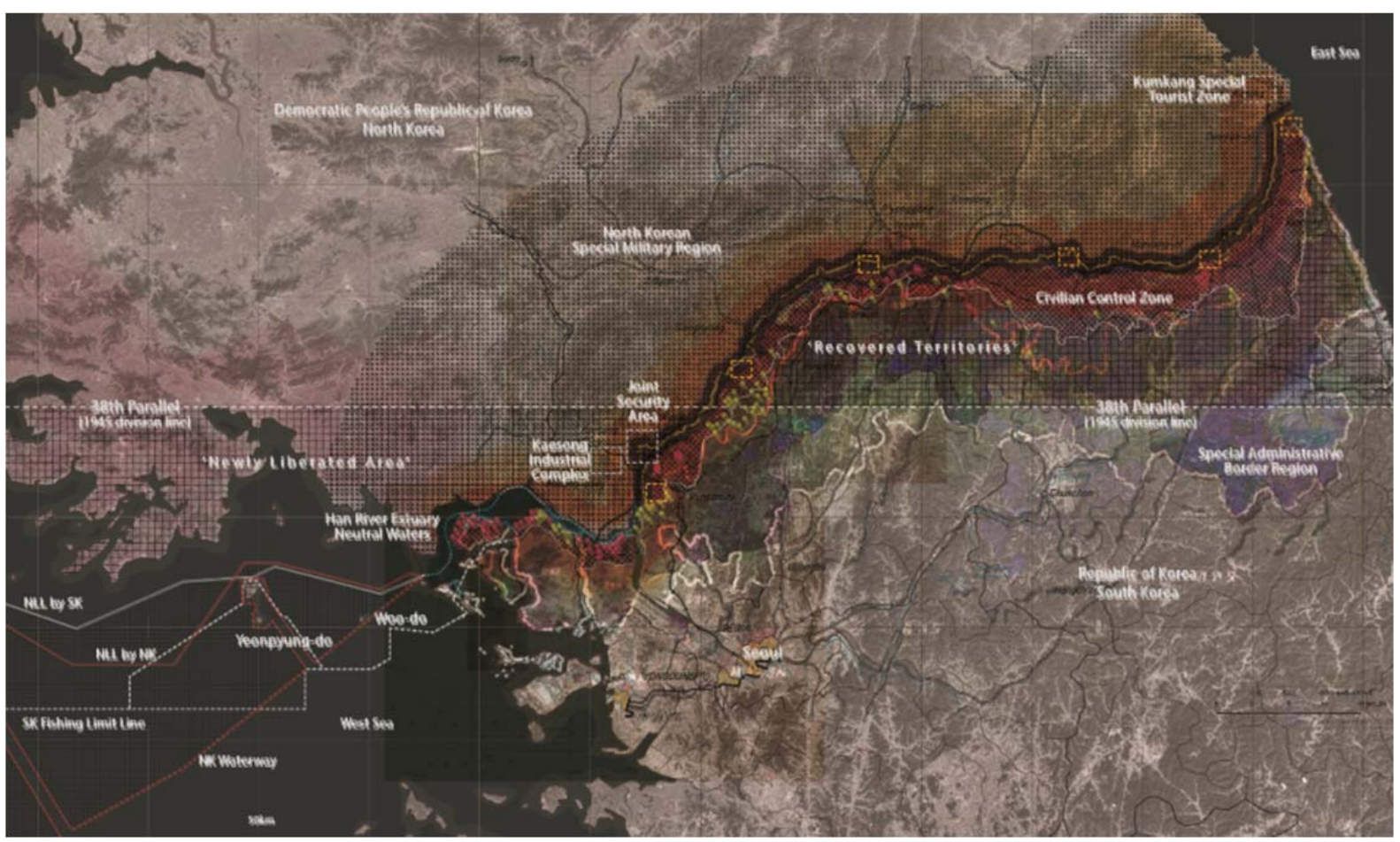

Figure I.Alex Young-II Seo.The multiple and somewhat instable and blurred inter-Korean borders.

\section{Sunee Yoo}

A refoundational simulative representation to multiply and reveal the spectacle At its core, this project is a reassemblage of delocalised and transplanted material, symbolic and behavioural elements and events that reveals the DMZ for what it is: a space saturated with political representations of power. Its restorative purpose informs the design of an agonistic infrastructure for new civic commons activated by creative acting of both local and translocal communities. Through parody and hyperbole, it develops a narrative that recodes selected perceived, interpreted and expressed spatialities. The new set of commons endorse free and autonomous understanding, expression and dialogue regarding the hugely variant, dynamic, and ever-changing questions of and attitudes towards the global DMZ.The parodic and satirical representation of key DMZ topoi-the strategic villages, loudspeakers and flag poles-is a political stance that encourages critically thinking of the apparatuses that they represent. The playful disassociation of these elements from their official representational narrative unveils their false appearance and establishes countering assemblages that initiate a foundative discourse around disrupted relationalities. By critically recombining, relocating and rerooting the monuments and scripted practices of this actualized theatre of the absurd, and eliciting the countering public expressions found all around the Korean Peninsula, the physical space of the DMZ is transformed into a garden of marvels that unfolds a full-blown political theatre (figures 2 and 3 ). 


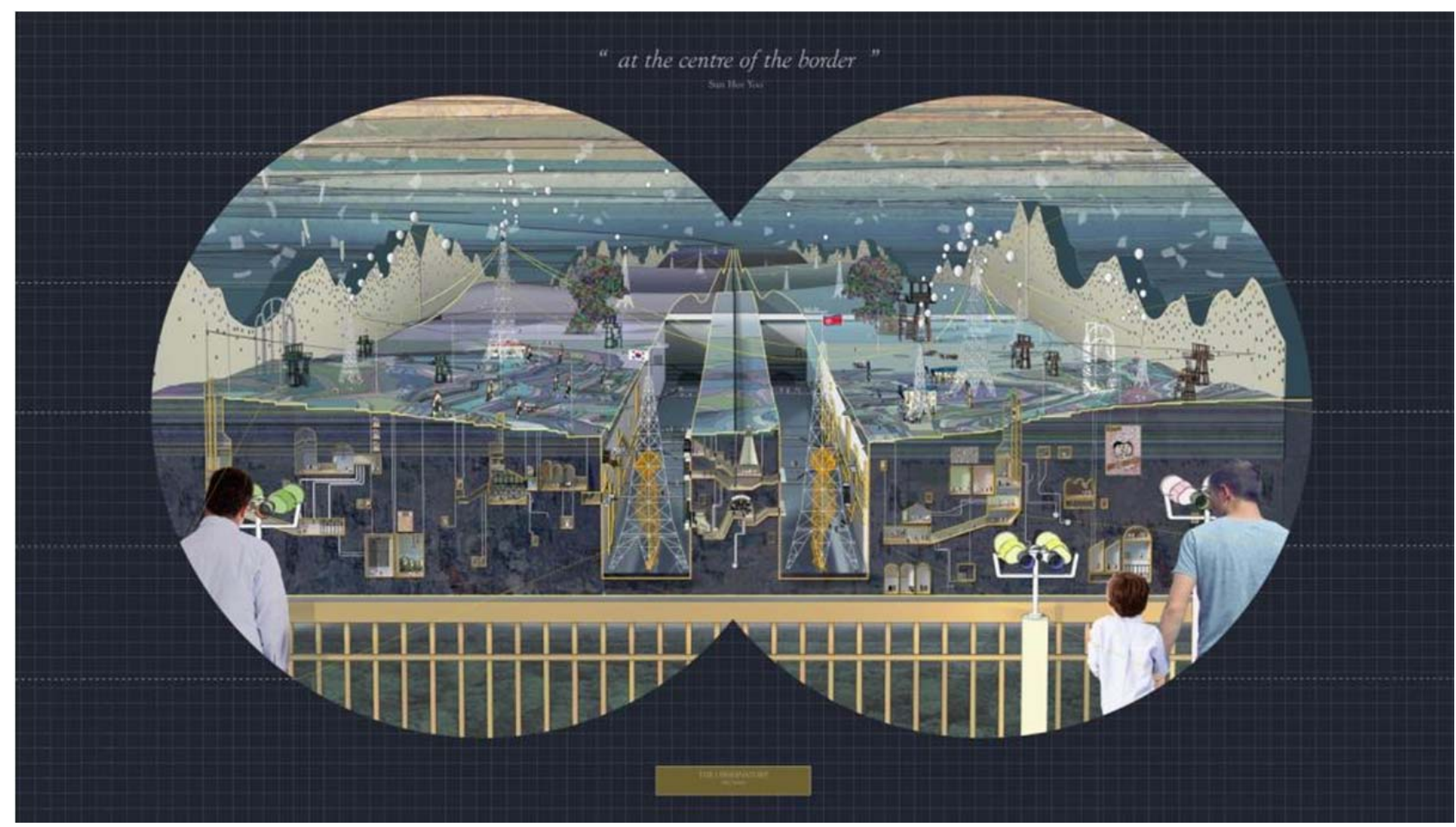

Figure 2. Sunee Yoo, Manfredini Studio.At the center of the border: binocular view of the 38th parallel north.

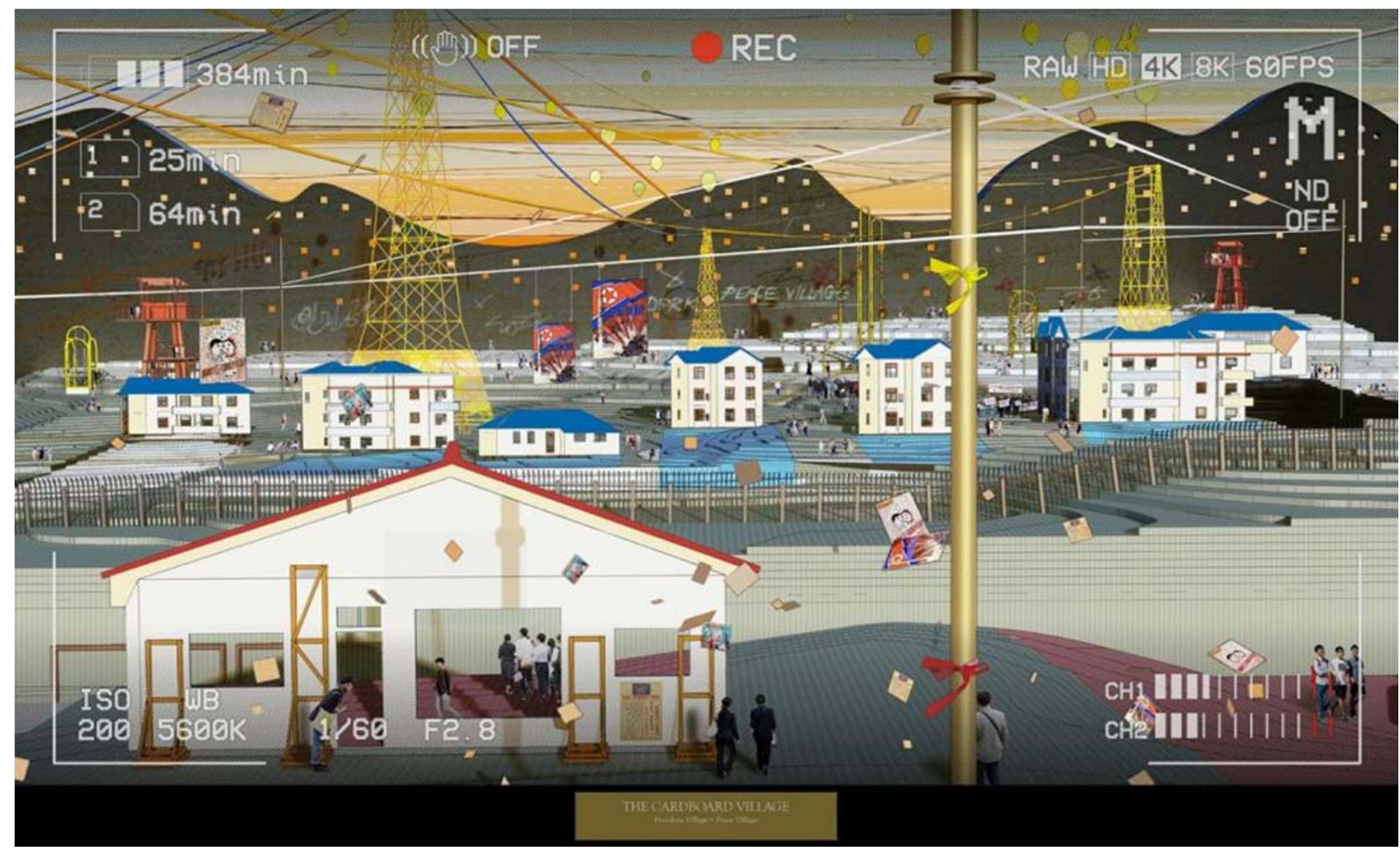

Figure 3. Sunee Yoo, Manfredini Studio. At the center of the border: North Korean "Peace village" seen from across the border. 


\section{Tamin Song}

Negating the spectacle, imploding representation

Our perception of history and becoming is manufactured through hagiographies that, in the case of wars, have their main embodiments in memorials, such as temples and barrows. The South and North Korean governments have constructed incongruous foundational narratives and biased stories of their common past. These curated representations of history are unable to communicate what they say they do: render the true, objective and holistic history of the country. The issue addressed by this project is not their ability to convey the truth but their pretension of doing so.


Figures 4 and 5. Tamin Song, Manfredini Studio. Memorial architecture for a reconciliating representational space.

Countering the existing self-assured representational narrative, it proposes a memorial of fragmented monuments of the DMZ, which strips back all commentaries and 
celebrative patterns to produce a space of emptiness and reflection. The bareness and disruption of information stimulates practices of reappropriation of values, rhythms and spaces. The memorial is a skeleton, which invites users to fill its void with independent acts and thoughts. The imploded representational constructs negate the rhetoric of spectacle and articulate a transient space that allows a multiplicity of interpretations of the shared traumatic past. The project is situated within the "super-nature" of the DMZ strip, a unique third landscape left unadulterated and non-curated since the war of the 1950s. Hidden inside a sealed ecological anthropotechnic sphere, a series of inaccessible pavilions, each alluding to the purely physical experience of the war, "the dead person's perspective," "fainting," "illusion," and "confusion," recast the monuments of hegemonic ideology into repositories of reassociative microstories (figures 4 and 5).

\section{Bruce Han}

Reprogramming the spectacle

The peculiar case of the Punggye-ri nuclear weapons test facility in North Korea has been investigated. Once a place that fuelled anxiety and conflict, the site is now an offering of peace with its televised demolition. Everything at Punggye-ri changed. Threat was cancelled and pacification fostered.

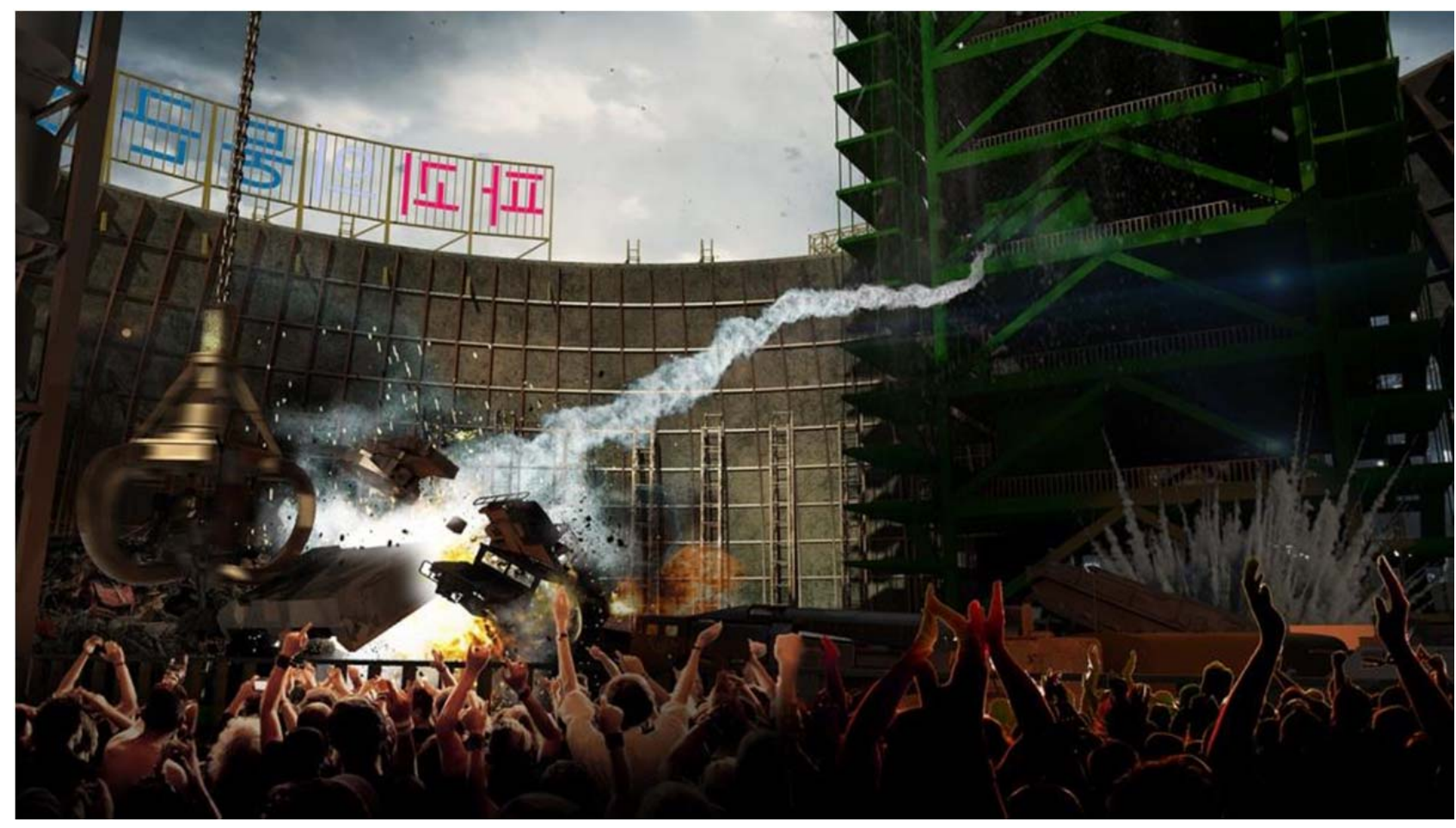

Figures 6. Bruce Han, Manfredini Studio. Reprogramming the spectacle: The repurposed Punggye-ri nuclear weapons test facility.

The project, elaborating upon the destruction process, entirely reprograms the site and recodes its spectacular symbols. By profoundly shifting the contexts, it drastically redefines the architectural and social space of this location. In this hypothetical scenario, reterritorialised Punggye-ri becomes a theatre for mass celebrations and festivals of free 
pro-unification movements. Instead of dismantling and destroying the relics of the warfare, the elements of a bygone war are recycled and refurbished. The narrative of violence is recast to constitute a forum of open dialogue and productive and agonistic conflicts (figure 6).

\section{Jin Woo Kuk}

Deprogrammed infrastructure for pluralistic agonism

This project investigates strategies of deprogramming to support an experiment of democracy grounded on pluralistic agonism principles, where the engagement of the occupants can lead to a collaborative and participatory production of the civic space of the extended city. A bridge-like infrastructure is constructed with dismantled parts of war machines along the base of the Demarcation Line.There is no predetermined function to this infrastructure as it is disengaged from the exogenous apparatus/system. By alluding to the function, but not prescribing it, this experimental and ambiguous meaningless structure (Jameson, 2007 [1992]) triggers provocative and unconditioned actions of North Koreans and South Koreans through spontaneous and creative interaction. The hard presence of the new infrastructure does not respond to a closed demand, instead it widens possibilities and diverse forms of civic space usage. Its counter-hegemonic and open articulation enables the radical recoding of the DMZ spatiality of power (figure 7).

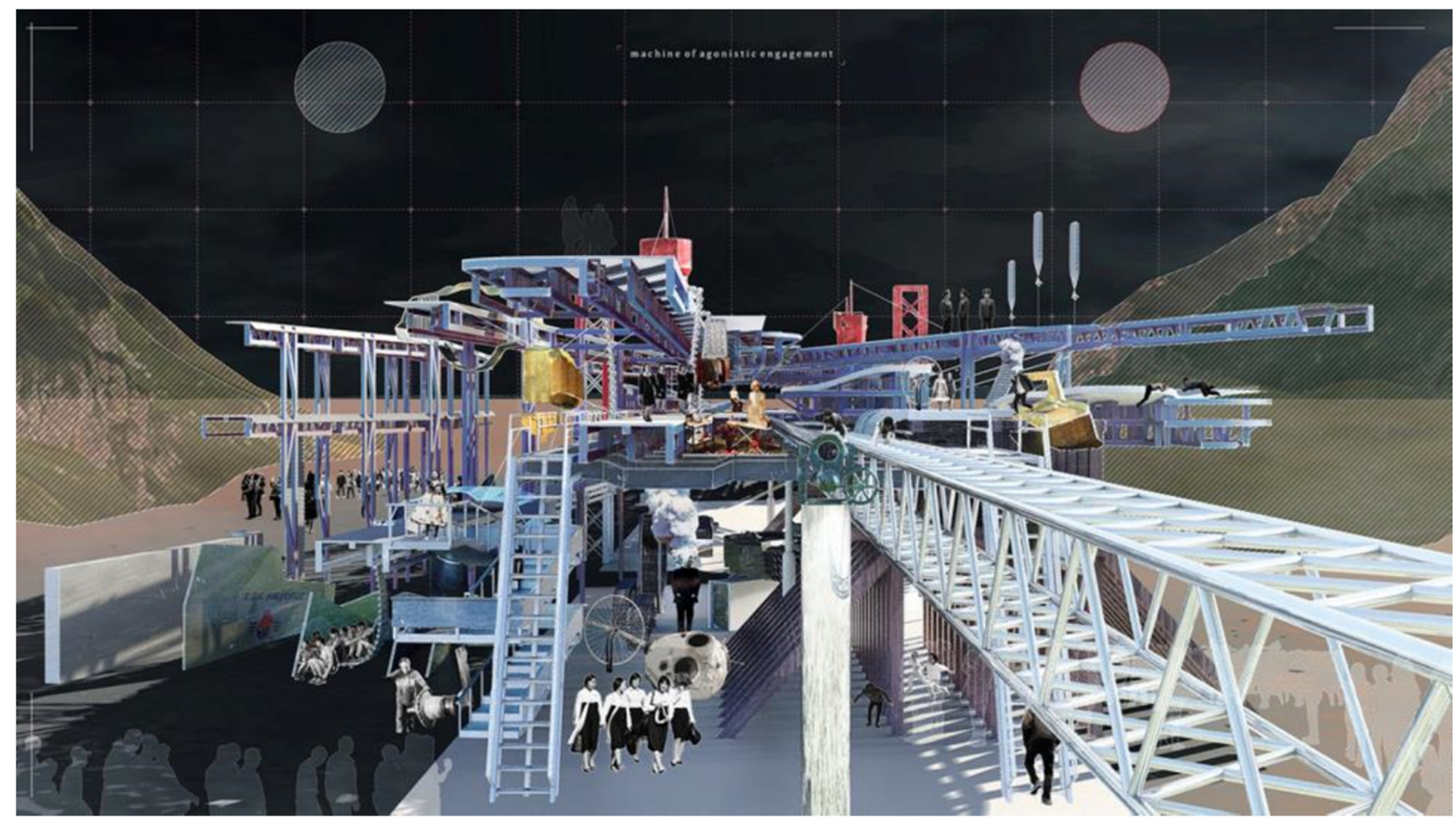

Figure7., Jin Woo Kuk, Manfredini Studio. Jameson's “meaningless structure” at the border. 


\section{Gangmin Yoo and Justin Baek}

Indeterminate and deprogrammed open infrastructure as the foundation for reconciliation in extra-territorial spaces.

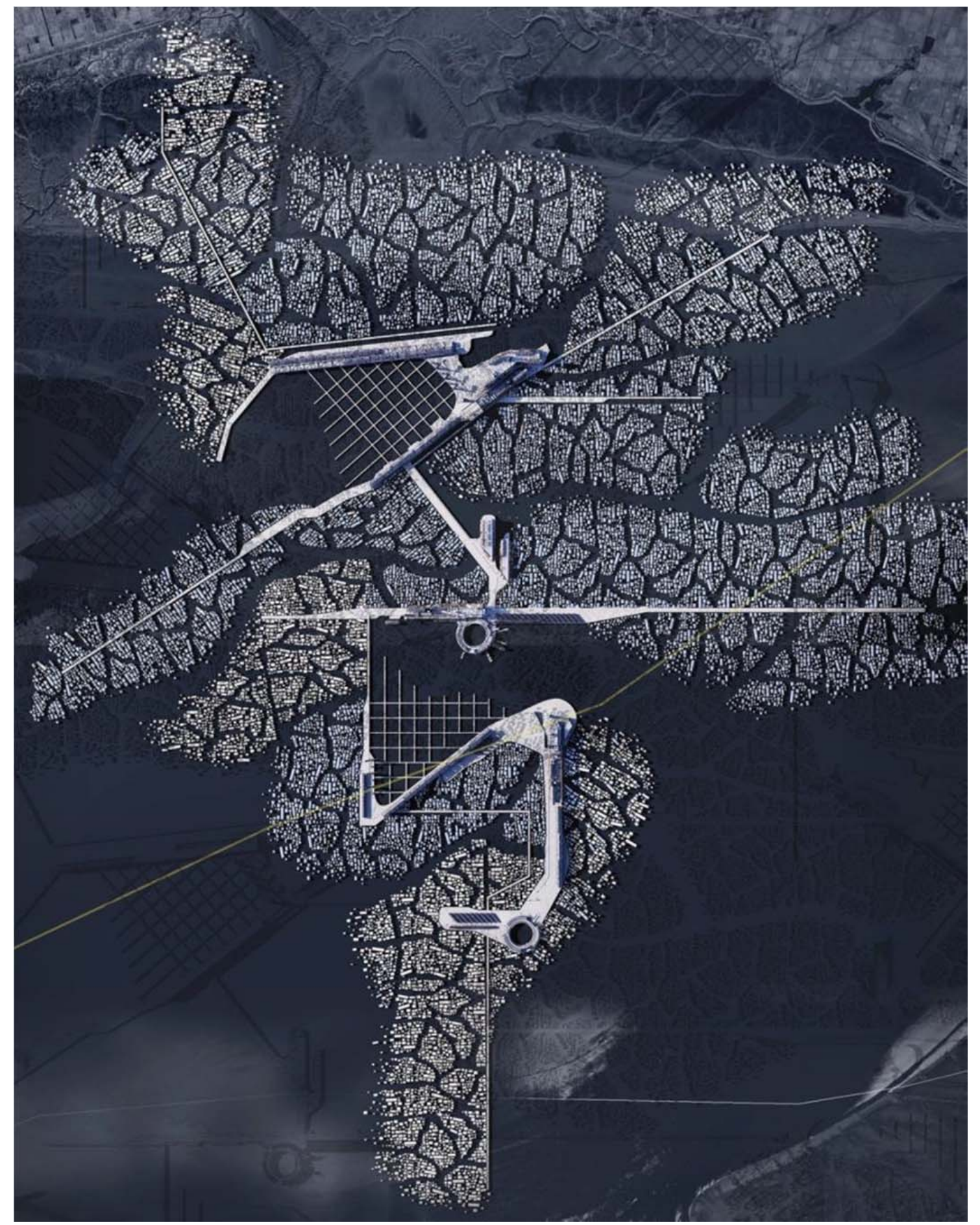

Figure 8, Gangmin Yoo and Justin Baek, Manfredini Studio.A floating settlement in the extra-territorial freespace of the Han River Estuary joint civilian waterway. 


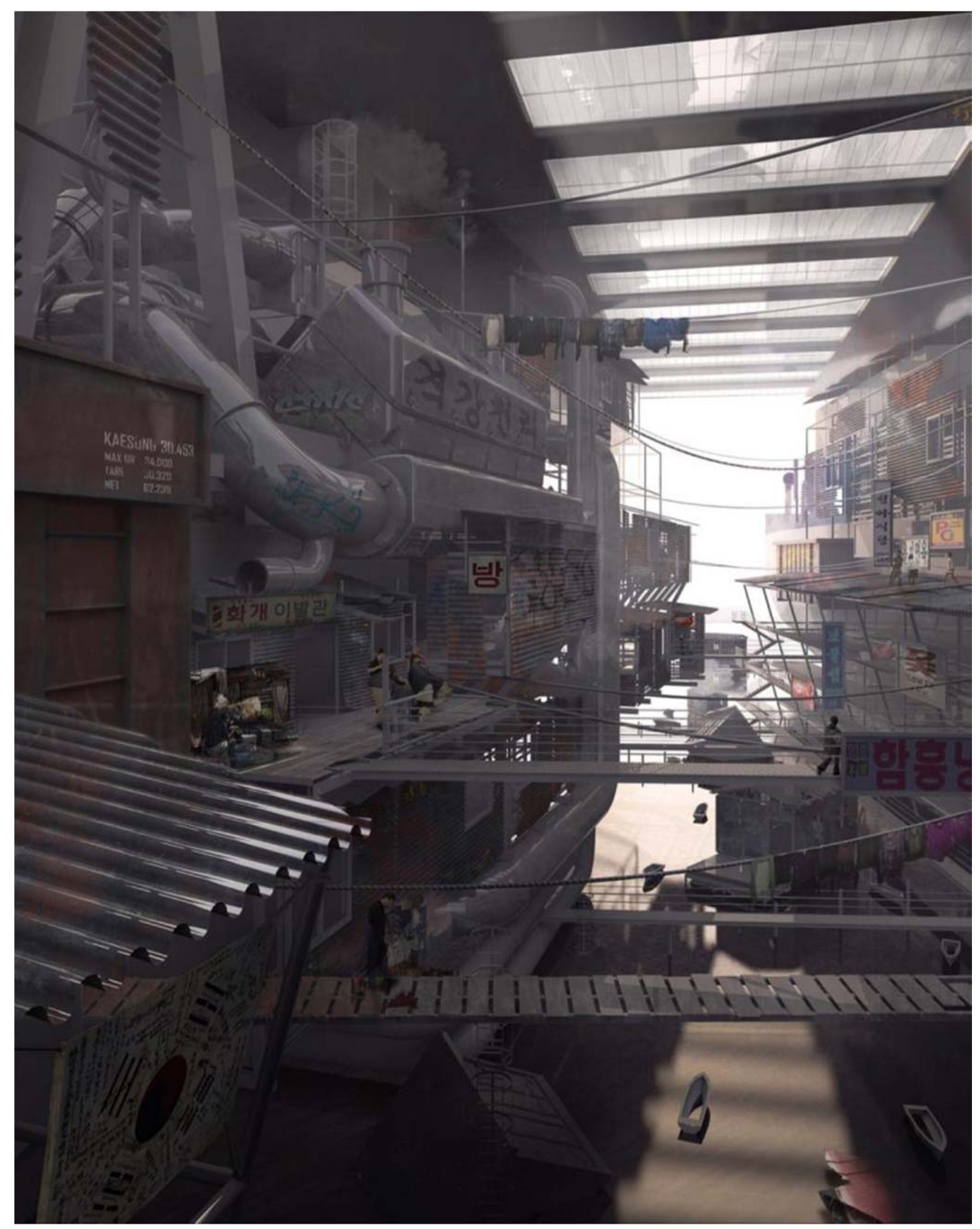

Figure 9, Gangmin Yoo, Manfredini Studio. Urban commons in the extra-territorial freespace of the Han River Estuary joint civilian waterway.

The identity of placeness is generated in the process of spatialised human interaction. In the DMZ, the vigorous process of homogenisation results in spaces deprived of placeness. Civilian access to the site of this project, the Neutral Zone in the Han River Estuary, was prohibited after the Korean War. In 1953, regulations were eased to permit the entry of few civilian ships under the jurisdiction of the two Koreas. Progressively, 
fishermen began trespassing the boundaries to seek new fishing areas. The project foresees the transformation of the neutral zone into an extra-territorial space where civilians remap the territory, deconstructing the apparatuses established by hegemonic (super)powers. Extra-territoriality enables the definition of a new heterotopic space where freedom replaces control. Collective amenities, such as fish processing and market facilities, are established in reappropriated spaces and armaments to support self-determination and independence. Over time, the incremental growth of these institutions and floating residences is expected to stabilise the floating settlement as a networked city of collaboration, commoning, identification and reinstituted placeness (figures 8 and 9).

\section{Sylvia Park MALL}

The Sylvia Park projects focus on freespace-the central theme of the 2018 Venice Architecture Biennale. Each work proposes a new infrastructure that enables the individuation of freespace in the realm advanced marginalisation of the centre. Through a critique of the fetishism of commodities that focuses on sign-values found in the everyday practices of reappropriative enjoyment, the projects explore the spaces of appearance (Arendt, 1958: 198-9) where goods enhance differentiation, celebrate particularity and thus establish a public dimension of collective commoning. Social, territorial and cultural elements of the prosaic are reconsidered and reassembled, and systems and devices of control and homogenisation are perverted.The hegemonic system of private economic forces is disestablished to reclaim the public right to the civic. Through speculative design processes, the projects produce a coordinated set of civic infrastructures for the core of the emerging associative urban space of Sylvia Park to promote active life and public engagement (figure 10).

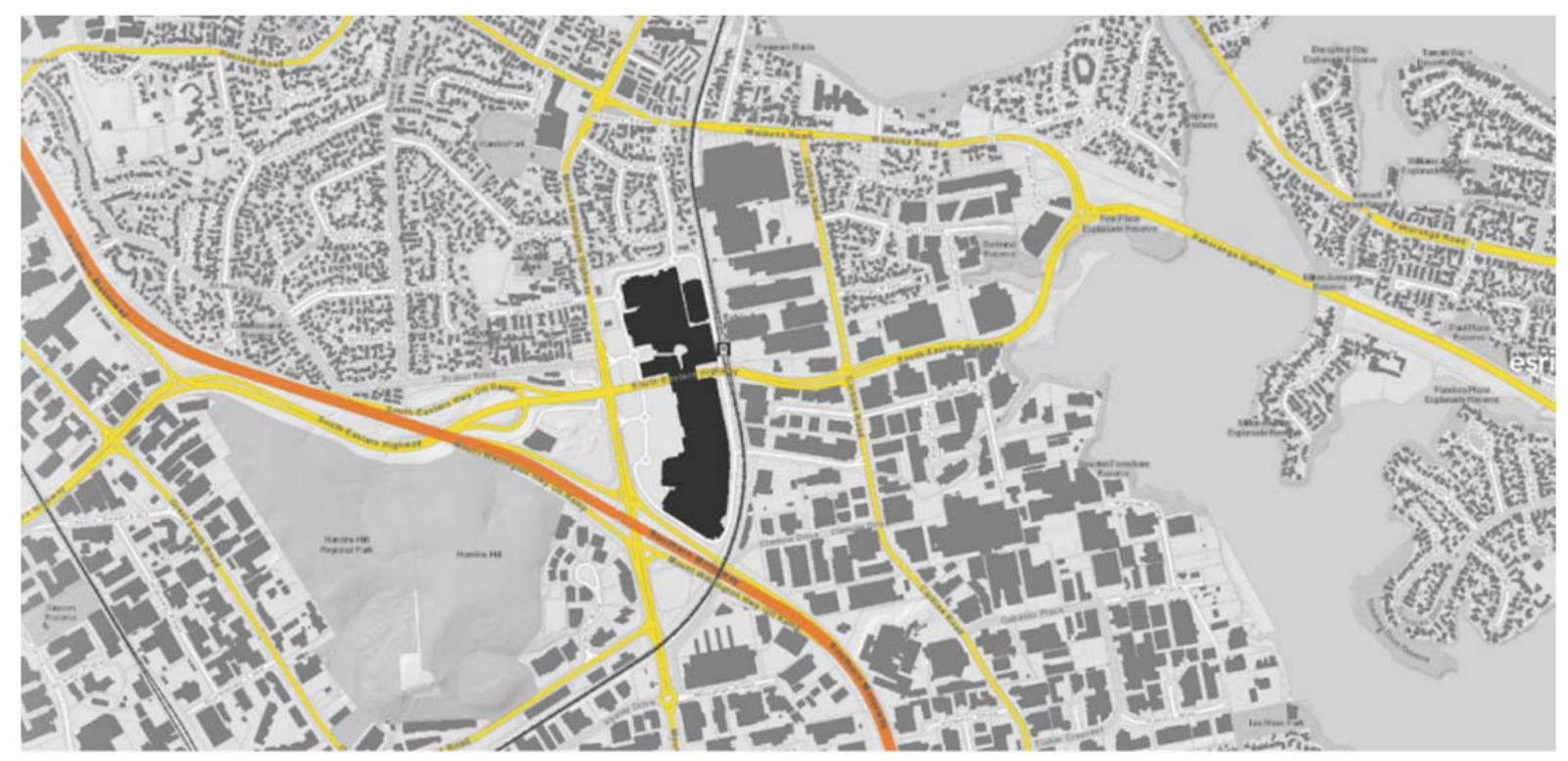

Figure 10, Sylvia Park Shopping Centre, one of the first-tier metropolitan centres of Auckland. The mall is a typical enclave of the "città elementare" (Viganò, 1999) between the northern ingraciated sea of distributed domesticity and the southern productive zone. Building footprint (the mall is the building in white). Source: https:// geomapspublic.aucklandcouncil.govt.nz/viewer/index.html (adapted by the authors) 


\section{Sunee Yoo}

Re-establishing the collective commons for the reidentification in the everyday life: The spectacularisation of the domestic in the civic space of modern suburbia.

The simulative spectacle of the MALL enclosure incorporates the domestic.A perfected and de-individualised pseudo-home reinterprets the New Zealand dream of the suburban house, illuminating it with style and technology. In the spectacular mirror of the MALL, the family house is dissected and each of its parts usurped by supersession: the living room is the representational arcade itself, the dining room the modish eatery, the bathroom the personalised spas, the backyard the green playgrounds. Reassociating the public expressions of the intimate self, this project inverses the heterotopia of the enclosed mall. It negates the transductive divide strategy of semi-public or pseudo-public enclosures, aiming to reinstate the power of the collective through celebration of its differential domestic prosaic practices. It addresses the existing tension between the commercial and the residential, the private and the public, of the Sylvia Park context.

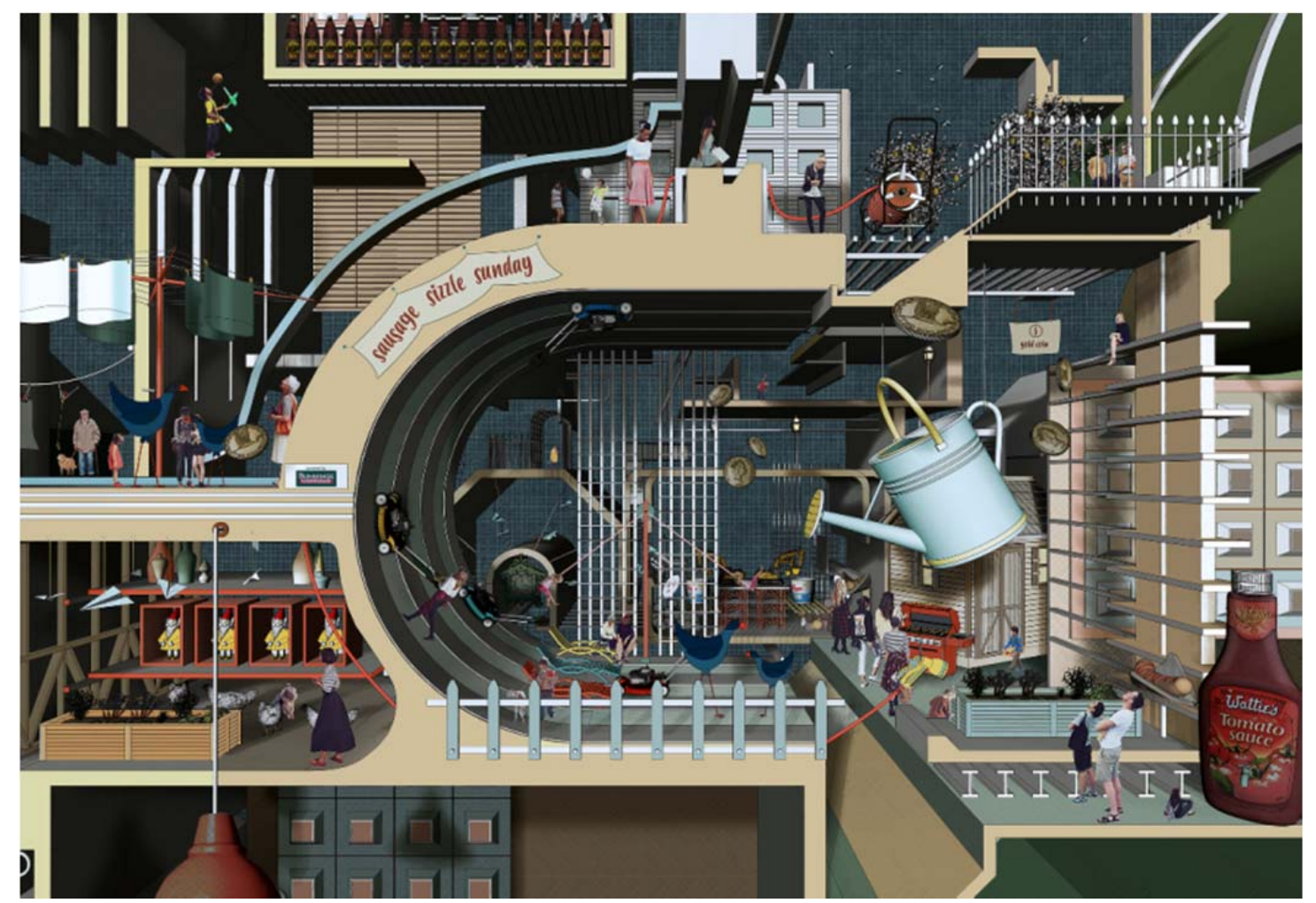

It proposes a theatre of the mundane where everyday domestic life is experienced publicly; a "space of appearance" that escapes the financialisation logic of the MALL to engage with the personal dimension. The project explores a fundamental recoding of value perception: a political theatre of domestic identity that celebrates the New Zealand locale, the familiar and the individual.Within this new domestic theatre, everyday objects are distorted in scale, displaced and misused, inviting domestic flaneurs to discover a new-found appreciation for and understanding of the unnoticed details of our lives. These domestic functions are exposed, exaggerated and overlapped to present a vibrantly interwoven public collective commons of democratic and pluralistic expression that restores freespace in the development of urban centres (figures II, I2 and I3). 



Figures II (previous page) and I2, Sunee Yoo, Manfredini Studio.

The political theatre of the domestic in the Mall: Backyard and bathroom scenes.

Figure 13. Sunee Yoo, Manfredini Studio.The political theatre of the domestic in the Mall: 


\section{Bryan Jung Ho Ahn}

Heterotopia of illusion: Little houses on the Hihillside, Little houses 'not' the same

The capacity of the pseudo-home of the MALL to displace and financialise the practices of the New Zealand dream by perfecting and de-individualising the places of the private sphere (see Sunee Yoo) is central to this proposition. By redefining and reframing its associational elements through the condition of density, the project establishes adequate conditions to each of the multiple spatialities in the transition between the domestic and the political. Community-led incrementalism as an alternative to centrally planned redevelopment is proposed as the driving process for an intensifying regeneration of the malled suburban centre. The progressive and cumulative assemblage of material elements and territorialities of the domestic tradition, those that are spatially compacted around core civic institutions and amenities, forms a hybrid heterarchical centre. The system is characterised by radical indeterminacy where every space is constantly re-appropriated and reprogrammed. The profound values of personal presence are intensified to support reidentification within the continuum house-to-commons space. The constant transformation supports a dynamic differentiation while negating abstraction and homogenisation through over-determination. The compacted territories collide to create a space birthing an agonistic heterarchical urban condition that liberates citizens from the division and distinction strategies of the city of consumption (figure 14).

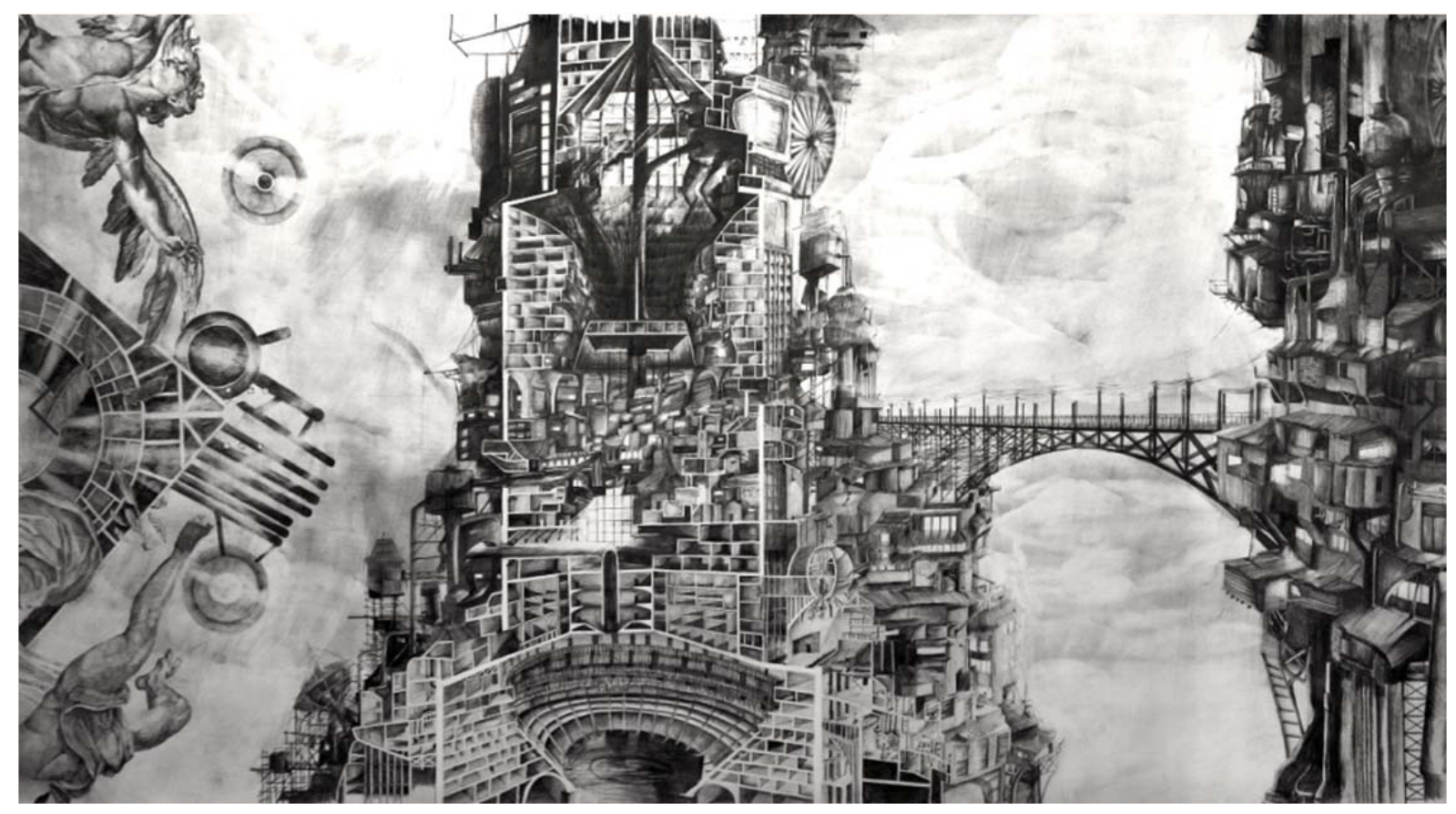

Figure 14. Bryan Jung Ho Ahn, Manfredini Studio. Vertical section and façade of the intensified suburban continuum house-to-commons space. 


\section{Sunjoo Lee}

Spatialising the commodity-body-sign question: reprogramming the consumerist spectacle to reestablish collective commons-private sphere continuum

This work studies post-consumerist processes in the space of hyper-consumption.

Advocating for autonomy and free expression, it envisions a new MALL that negates the strategies of expansionist economic forces and reprograms the practices of consumption. Accumulations of personal goods originated from excessive consumption, which typically include countless out-of-fashion shoes, bags, jewellery or watches, are cast into curated collections. It proposes to address the essential problem of consumerism by considering how the quantitative question should include that of the self, regarding personal investment, interpretation, memory, representation and association. In the mall, spatial interfaces between object and patron are driven by private programmed-obsolescence models of capital-accumulation strategies. These spatial interfaces are the prime material agents of the vicious cycle of repeated purchase based on impermanent values that the apparatus induces.

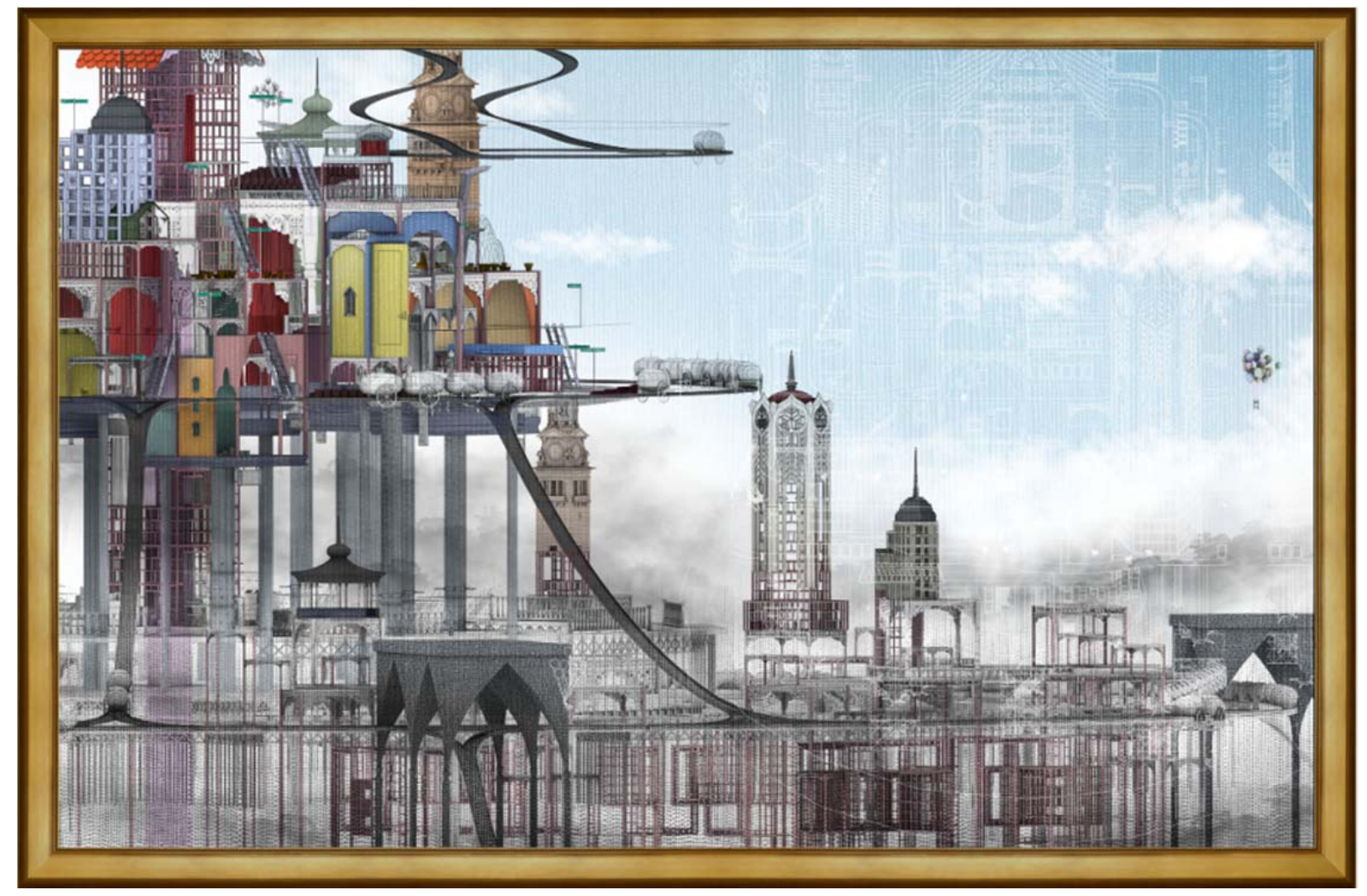

The research recognises the innate associative human desire and, rather than simply individualise it, it explores the potential of collective commons to conserve, share, exchange and merge the assemblages that constitute and identify the individual and its social, spatial and cultural belongings. Reprogramming spaces of the consumption processes, the project manipulates the spatial interface of trade to recode the shortlived value perception of the commodities. The proposed system is not based on objects' rapid value depreciation, but the affirmation of the embedded use and signvalues. In this new context, traded objects are displayed in curated collections like those 
of museums. A theatrical kaleidoscope machine as a "space of appearance" (Arendt 1958) designed to reappropriate, reassemble and publicly share personal consumerist experiences. A productive repetition assemblage constitutes the new institution, using as main reference the domestic veranda, the most iconic interface between the private and the public. The collections are displayed in moving verandas speaking to the identity and character of not only the object itself but also of its owner. This "space of appearance" becomes an interface that enables confrontation and dialogue, affirming the diversity of the self and fostering freespace (figures 15 and 16 ).

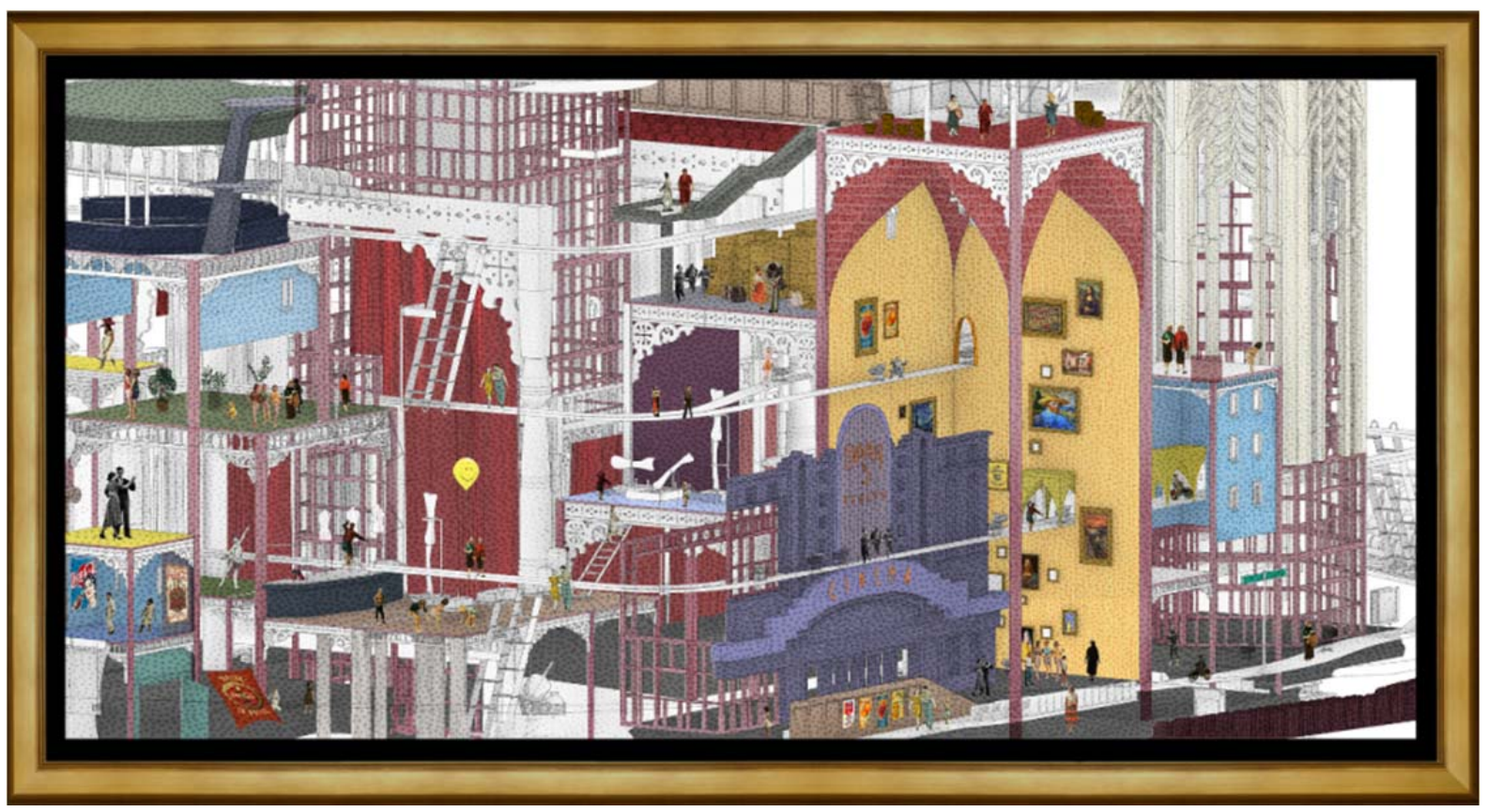

Figures 15 and 16, Sunjoo Lee, Manfredini Studio. The theatrical kaleidoscope machine for reappropriation, reassembling and publicly share personal consumerist experiences.

\section{Gangmin Jono Yoo.}

Radical deMALLing: rediscovering the capacity of space to support trangressive acting that liberates creativity and establishes pluralistic agonism

Productive transgression is at the basis of genuine creative acts that strengthen identity, association, differentiation and awareness. These acts overcome the constraints of apparatuses that fragment, control and alienate our physical, social, cultural and psychological experiences. Such transgression is specific to processes where boundaries, both tangible and intangible, originate deterritorialisations and reterritorialisation processes for the reappropriation of spaces and practices that affirm the right to the city. Heterotopic territories with imperative boundaries such as the MALL enable coordinated acts of transgression, becoming laboratories for alternative modes of production that transform the dominating condition of abstraction into one of liberating communing. This project explores existing antagonist practices, such as independent socialisation, expression and barter and their material production of alternative territorial markers (e.g., graffiti), boundary openings (e.g., access through burglar paths) 
and productive units (e.g., night market kitchens). These practices are used to envision a scenario where "spatial criminals" reconquer the privatised and financialised public space of the MALL by deconstructing and reprogramming its hegemonic infrastructural determinants (figures 17 and 18 ).

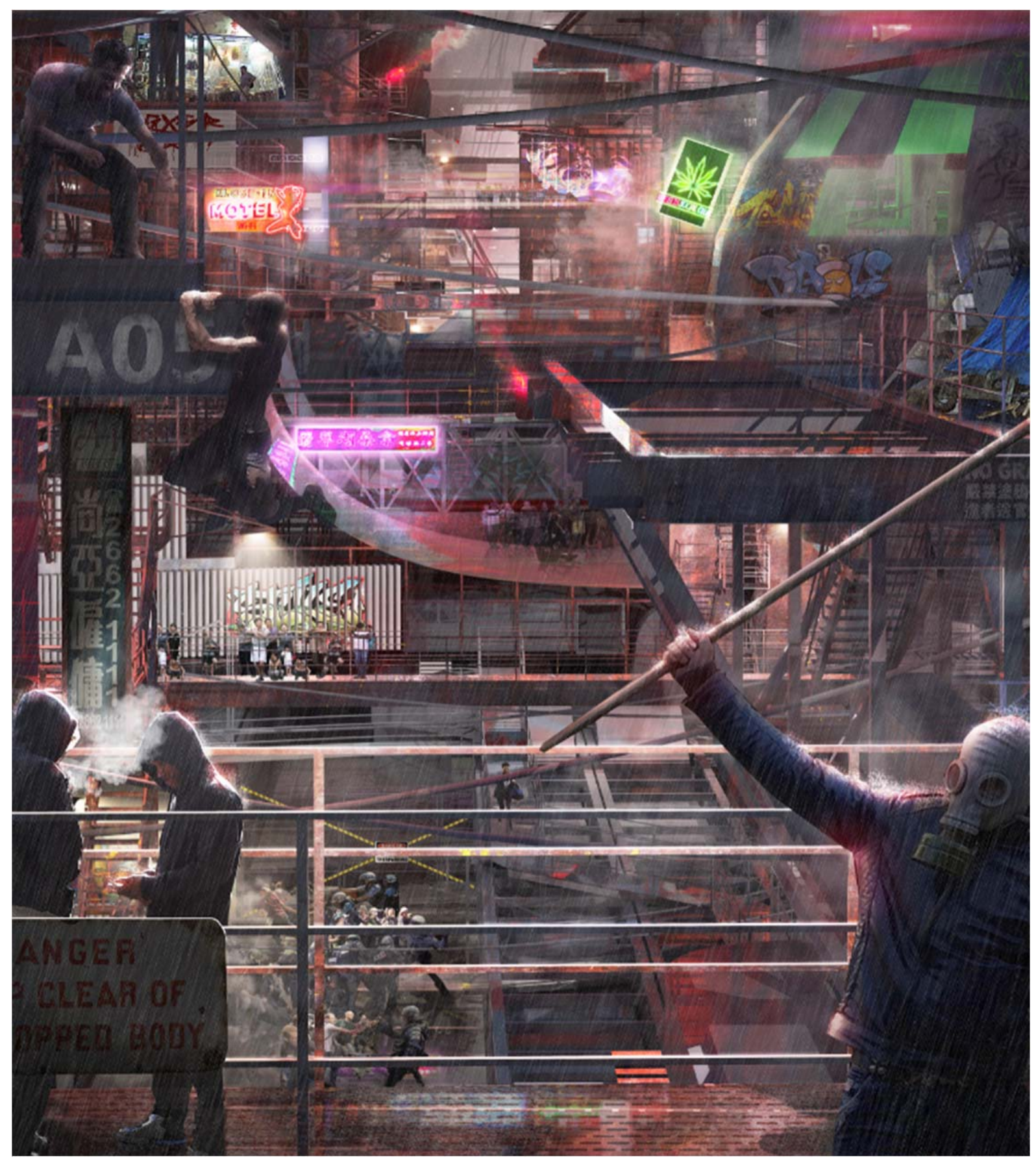

Figure 17 and 18 (next page). Gangmin Jono Yoo, Manfredini Studio. Laboratories for alternative modes of production in reappropriated heterotopic territories of consumption. 


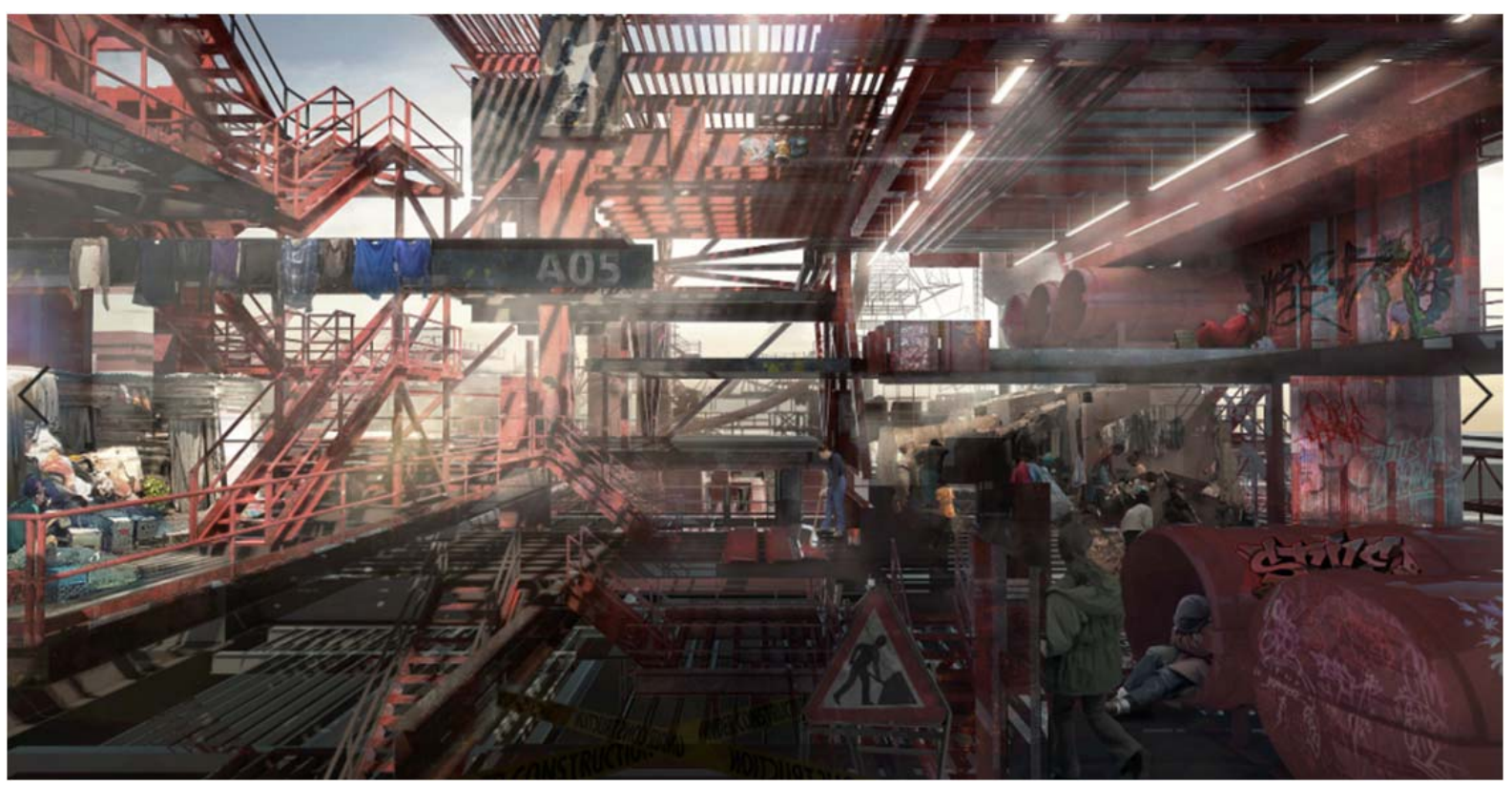

\section{Scott Ma}

Autopia: The automobile as vehicle of reappropriation

This project explores the issue of contemporary consumerist culture by examining the impact of the automobile on the deterritorialisation and reterritorialisation of public space. It focuses on instances of subversive practices that make the automobile a catalyst of reassociational and reassociative social, cultural and poietic practices. The modern urban form, infrastructures and landscape have been shaped by the car. Car-oriented development has originated urban sprawl with low dwelling density, limited accessibility (particularly with public transport) and minimal pedestrian movement. Despite being based on a mode of transport that brings people closer, it has produced distributed, fragmented and disconnected urban communities. New Zealand's suburban malls epitomise this urban development model. This project takes an allegorical approach, reimagining a city produced by car counterculture. It articulates a narrative where the car is the centre of human practices and desires. Rather than control all aspects of our everyday life, it allows moments of individual autonomy and auto-determination. It constitutes an assemblage between elements, providing capacity for elements to be combined and recombined in a way that would otherwise be impossible. The carpark cathedral (figure 19) and the drive-in love theme hotel (figure 20) are proxies for identifying and understanding the liberating potential of the car in our urban society. They expose the absence of specific infrastructure for varied interpersonal relations to develop, and thus the car, which has become the most easily customisable private space of the modern citizen, is reappropriated for this purpose. This intriguing relationship between car and auto(car)-determination of the city and auto(self)-determination of space and personal identity is where the project rediscovers the car as a catalyst for freespace.

Figure 19 and 20 (next pages). Scott Ma, Manfredini Studio, the city of car counterculture: Carpark cathedral and Drive-in love theme hotel as affirmative institutions of individual autonomy and auto-determination. 


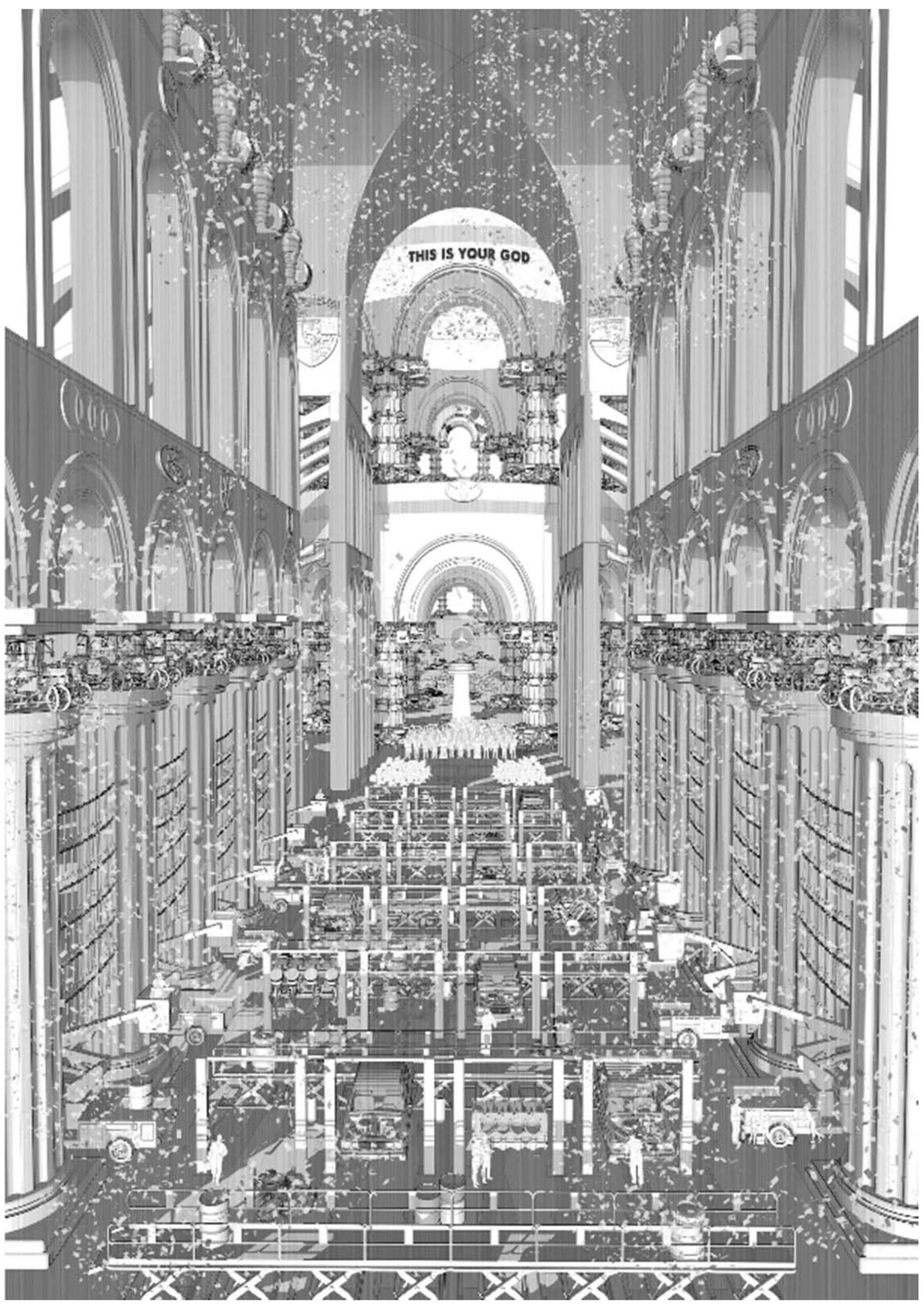




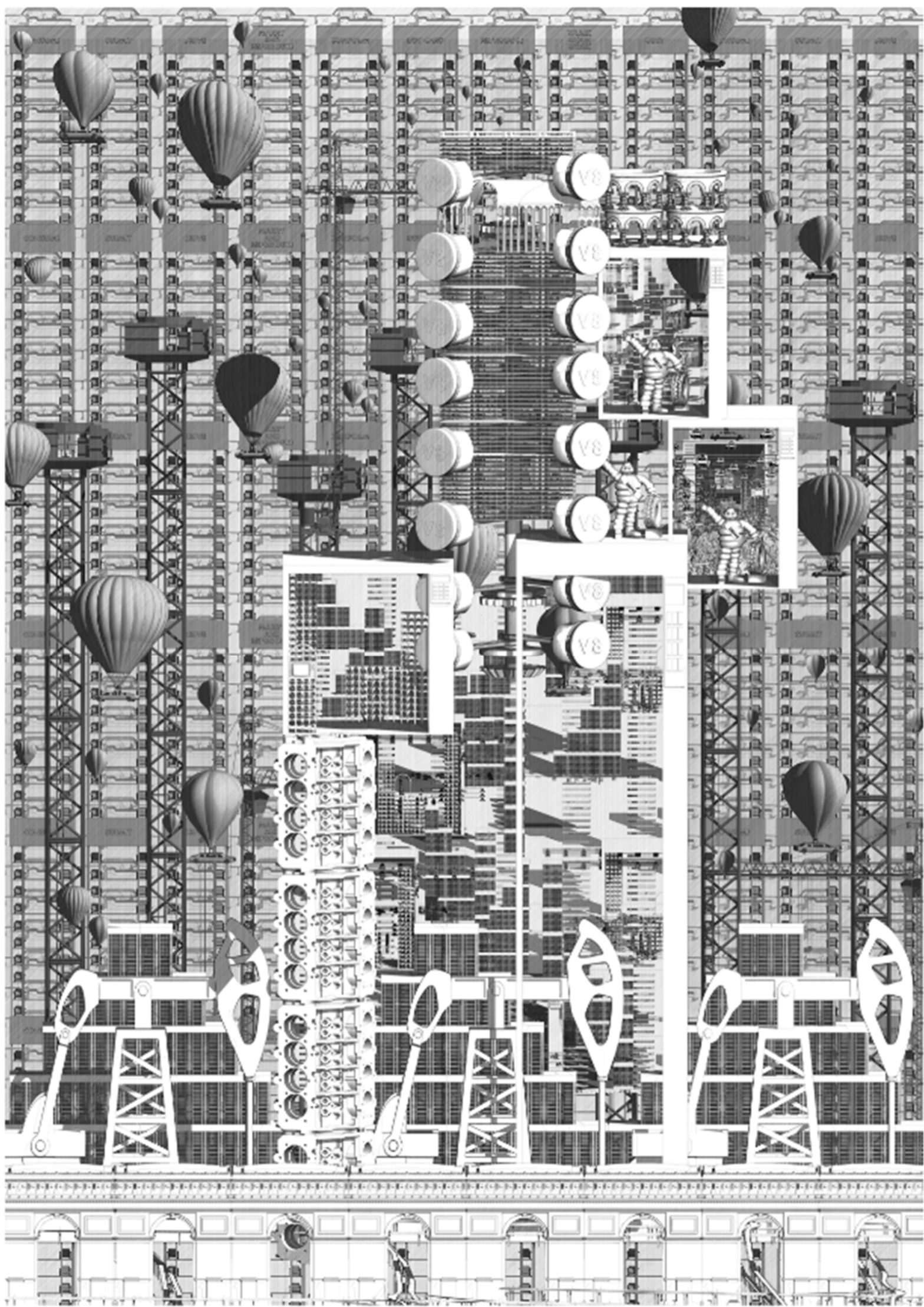

106 | The Journal of Public Space, 4(4), 2019| ISSN 2206-9658

City Space Architecture / UN-Habitat 


\section{References}

Brickell, Katherine and Datta, Ayona (eds.) (20I I). Translocal geographies: Spaces, places, connections. Burlington, VT:Ashgate.

Calhoun, Craig (1992). Introduction: Habermas and the public sphere, in Craig Calhoun (ed.), Habermas and the public sphere. Studies in contemporary German social thought. Cambridge, MA: MIT Press, Pp. I-50.

Castells, Manuel (2000). The rise of the network society. 2nd Edition. London: Edward Elgar.

Connolly, William E. (2005). The evangelical-capitalist resonance machine. Political Theory, 33, pp. 869-886.

Dehaene Michiel and De Cauter, Lieven (2008). Heterotopia:A postcivil society, in Michiel Dehaene and Lieven De Cauter (Eds.), Heterotopia and the city: Public space in a postcivil society. Abingdon, Oxon: Routledge, Pp. 3-9.

Deleuze, Gilles and Guattari, Félix (1983). Anti-Oedipus: Capitalism and schizophrenia. Minneapolis: University of Minnesota Press.

Foth, Marcus, Brynskov, Martin and Ojala, Timo (Eds.) (20I5). Citizen's right to the digital city: Urban interfaces, activism, and placemaking. Singapore: Springer.

Fuchs, Christian (20I4). Social media and the public sphere. TripleC, I2, pp. 57-I0I.

Gelézeau,Valérie (20II). The inter-Korean border region - 'meta-border' of the Cold War and metamorphic frontier of the peninsula, in Doris Wastl-Walter (Ed.), The Ashgate research companion to border studies. Oxon:Ashgate, pp. 325-348.

Greiner, Clemens and Sakdapolrak, Patrick (20I3). Translocality: Concepts, applications and emerging research perspectives. Geography Compass, 7, 5, pp. 373-384.

Harvey, David (2008). The right to the city. New Left Review, 53, pp. 23-40.

Harvey, David (20I I). The future of the commons. Radical History Review, 109, pp. I0I-107.

Horvath, Agnes, Bența, Marius lon and Davison, Joan (Eds.) (2019). Walling, boundaries and liminality:A political anthropology of transformations. Oxon: Routledge.

Jameson, Fredric and Speaks, Michael (1992). Envelopes and enclaves:The space of post-civil society (an architectural conversation). Assemblage, 17, pp. 30-37.

Kazig, Rainer, Masson, Damien and Thomas, Rachel (2017). Atmospheres and mobility. An introduction. Mobile Culture Studies, 3, pp. 7-20.

Kim, Nan (2015). Memory, reconciliation, and reunions in South Korea: Crossing the divide. Lanham, MD: Lexington Books.

Koolhaas, Rem (2002). Junkspace. Obsolescence, I00, pp. I75-190.

Lefebvre, Henri (1991 [1974]). The production of space. Oxford: Blackwell.

Lefebvre, Henri (2003 [1970]).The urban revolution. Minneapolis: University of Minnesota Press.

Linebaugh, Peter (2007). Magna Carta manifesto: Liberties and commons for all. Berkeley: University of California Press.

MacKenzie, Adrian (2006). Transductions: Bodies and machines at speed, London: Continuum.

Manfredini, Manfredo (20I7). The augmented meta-public space. Interpreting emerging transductive territories in enhanced centres of consumption. The Journal of Public Space 2(3), Pp. III-I 28.

Manfredini, Manfredo (2019a). Emerging spatialisations of resilient urban commons: Re-thinking associative networks in the age of advanced translocalism, transduction and metapublicness. In Beyond Resilience:Towards a More Integrated and Inclusive Urban Design. Proceedings of the 12th Conference of the International Forum on Urbanism, Jakarta, 2426 June 2019.

Manfredini, Manfredo (20/9b). Give us space, research synthesis report. Retrieved from www.drh.nz/analytical-tools-main-page/. 
Manfredini, Manfredo (2019c). Simulation, control and desire: Urban commons and semi-public space resilience in the age of augmented transductive territorial production. The Journal of Public Space, 4(2), pp. I79- 198.

Manfredini, Manfredo (2019d). Travels in Woundedland: Manfredo Manfredini for the Shenzhen Biennale (UABB) 2019, Archdaily. Retrieved from https://www.archdaily.com/929175/travels-in-woundedland-manfredo-manfredini-for-theshenzhen-biennale-uabb-2019.

Manfredini, Manfredo, Zamani Gharaghooshi, Farzad and Leardini, Paola (2017). Instances of emerging agonistic spatialities in the contemporary city:The production of differential geographies in the public space of Istanbul. Asian Journal of Humanities and Social Studies, 5(5), pp. 28I-29I.

Merrifield, Andy (2000). Henri Lefebvre:A socialist in space, in Mike Crang and Nigel Thrift (Eds.), Thinking Space. London: Routledge, p. 76.

Mouffe, Chantal (2008). Public spaces and democratic politics, in Jeroen Boomgaard (Ed.), Highrise-Common ground. Art and the Amsterdam Zuidas area.Amsterdam:Valiz, pp. I35-I56.

Purcell, Marc (2003). Citizenship and the right to the global city: Reimagining the capitalist world order. International Journal of Urban and Regional Research, 27, p. 578.

Purcell, Marc (2014). Possible worlds: Henri Lefebvre and the right to the city, Journal of Urban Affairs, 36, I, Pp. I4I-I54.

Ritzer, George (2005). Enchanting a disenchanted world: Revolutionizing the means of consumption. London: Pine Forge Press.

Sennett, Richard (2018). Building and dwelling: Ethics for the city. New York: Farrar, Straus and Giroux.

Seo, Alex Young-II (2018). From disorderly dispersion to orderly concentration: Frontier villages at the Korean border 195I-1 973. Scroope:The Cambridge Architecture Journal, 27, pp. 43-58.

Simondon, Gilbert (2013 [1964-89]). L'individuation à la lumière des notions de formes et d'information. Paris: Edition Jérôme Millon. 